\title{
Senyawa Bufadienolida yang bersifat Insektisida, Daigremontianin dari daun Cocor Bebek (Kalanchoe daigremontiana)
}

\author{
Tri Mayanti, Desi Harneti Putri Huspa, Nurlelasari, Agus Safari, Unang Supratman* \\ Jurusan Kimia, Fakultas Matematika dan Ilmu Pengetahuan Alam, \\ Universitas Padjadjaran, Jalan Raya Bandung-Sumedang KM 21, Jatinangor, 45363 Sumedang 40600 \\ e-mail: u_supratman@,unpad.ac.id
}

\begin{abstract}
Abstrak
Dalam penelitian berkelanjutan untuk pencarian senyawa-senyawa yang bersifat insektisida dari tanaman Kalanchoe (Cocor bebek) Indonesia, diperoleh hasil bahwa ekstrak metanol daun Cocor bebek (Kalanchoe daigremontiana) memberikan aktivitas insektisida yang kuat terhadap instar ke tiga larva ulat sutera (Bombyx mori). Ekstrak metanol yang diperoleh selanjutnya dipisahkan senyawasenyawanya menggunakan partisi dengan pelarut organik dan kombinasi kolom kromatografi pada silika gel dan ODS sehingga dihasilkan satu senyawa aktif insektisida. Struktur kimia senyawa yang bersifat insektisida tersebut ditentukan dengan metoda spektroskopi dan perbandingan data spektra senyawa analog yang telah diperoleh dari penelitian sebelumnya sehingga senyawa aktif insektisida tersebut diidentifikasikan sebagai senyawa turunan bufadienolida, daigremontianin. Daegremontianin menunjukkan aktivitas insektisidal yang kuat terhadap instar ke tiga ulat sutera (Bombyx mori) dengan $\mathrm{LD}_{50} 0,9 \mu \mathrm{g} / \mathrm{g}$ diet.
\end{abstract}

Kata kunci : Kalanchoe; Crassulaceae; Bufadienolide; aktivitas insektisida, Kalanchoe daigremontiana

\begin{abstract}
In the course of our continuing search for novel insectisidal compound from Indonesian Kalanchoe plants, the methanolic extract of the leaves of Cocor bebek (Kalanchoe daegremontiana) showed strong insecticidal activity against the third instar larvae of silkworm (Bombyx mori). The methanol extract was separated their compound by organic solvent partition and column chromatography on Silica gel and ODS to yield an active compound. The chemical structure of an active compound was elucidated by spectroscopic method and comparison with those related data previous reported and identified as a bufadienolide derivate compound, daigremontianin. Daigremontianin showed strong insecticidal activity against the third instar larvae of silkworm as a LD50 $0.9 \mu \mathrm{g} / \mathrm{g}$ diet.
\end{abstract}

Kata kunci : Kalanchoe; Crassulaceae; Bufadienolide; insecticidal activity, Kalanchoe daigremontiana

\section{PENDAHULUAN}

Selama lima dasawarsa terakhir, insektisida konvensional seperti hidrokarbon terklorinasi, organofosfat, karbamat, dan piretroid telah berhasil mengendalikan hama pertanian, tetapi, kebanyakan bahan kimia dari insektisida konvensional ini dapat merugikan kehidupan manusia dan organisme menguntungkan lainnya serta dapat mengganggu kehidupan ekosistem. Meskipun berbagai usaha telah dilakukan untuk meminimalisasi dampak negatif terhadap lingkungan, tetapi tuntutan terhadap keselamatan lingkungan dan penggunaan insektisida yang lebih selektif terhadap hama tertentu semakin meningkat. ${ }^{1)}$ Pada saat ini kebutuhan akan pengendalian hama di bidang pertanian semakin meningkat, dan perhatian kembali diarahkan terhadap bahan alam karena dapat mengurangi dampak negatif 
terhadap lingkungan dan lebih spesifik terhadap jenis hama tertentu. ${ }^{2)}$

Senyawa bioaktif yang diperoleh dari bahan alam selain daya racunnya masih tetap tinggi, juga mudah mengalami biodegradasi yang tidak membahayakan lingkungan. Hal ini didasarkan pada struktur kimianya yang umumnya terdiri dari karbon, hidrogen, oksigen, dan nitrogen. ${ }^{3)}$ Ekstrak tumbuhan telah lama digunakan sebagai insektisida oleh manusia sebelum masa Romawi. ${ }^{4)}$ Beberapa insektisida penting yang telah digunakan secara luas di bidang Pertanian yang berasal dari tumbuhan adalah rotenon, ${ }^{5}$ piretrin, ${ }^{6}$ dan anabasin. ${ }^{7}$ Perlu ditekankan bahwa kebanyakan tumbuhan yang memiliki aktivitas insektisida berasal dari tumbuhan tropis.

Dalam kegiatan penelitian berkelanjutan kami terhadap pencarian senyawa-senyawa insektisida baru dari tanaman Kalanchoe Indonesia, kami telah mengisolasi dan menjelaskan dua senyawa bufadienolida yang bersifat insektisida, dari daun Kalanchoe pinnata, ${ }^{8)}$ empat senyawa bufadienolida yang bersifat insektisida dari daun Kalanchoe daigremontiana x tubiflo. ${ }^{9)}$ Dalam penelitian lanjutan terhadap senyawa-senyawa insektisida dari tanaman Kalanchoe Indonesia (syn. Bryophyllum), kami menemukan bahwa ekstrak metanol daun Kalanchoe daigremontiana memberikan aktivitas insektisida yang kuat terhadap instar ke tiga ulat sutera (Bombyx mori).

Kalanchoe daigremontiana (Crassulaceae, dikenal sebagai tanaman "cocor bebek" di Indonesia adalah tanaman herba yang tumbuh sepanjang tahun dan mempunyai daun yang berair. ${ }^{10)}$ Tanaman ini di kenal di masyarakat Indonesia untuk penanggulangan berbagai penyakit diantaranya demam, batuk, dan berbagai penyakit kulit. ${ }^{11)}$ Penelitian terhadap kandungan kimia tumbuhan $K$. daigremontiana dilaporkan mengandung sterol dan bufadienolida, ${ }^{12)}$ tetapi kandungan senyawa yang bersifat insektisida belum diketahui. Dalam makalah ini, kami akan melaporkan isolasi, penentuan struktur senyawa yang bersifat insektisida, dan aktivitas insektisidal senyawa daigremontianin yang diperoleh dari daun Kalanchoe daigremontiana.

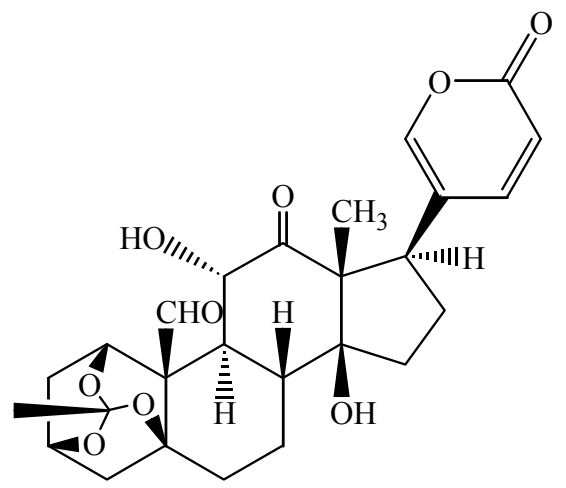

Gambar 1. Struktur senyawa Daigremontianin

\section{METODE PENELITIAN}

\section{Bahan tanaman}

Daun tanaman cocor bebek (Kalanchoe daigremontiana) dikumpulkan dari kebun percobaan di daerah Bandung, Jawa Barat, Indonesia pada bulan September 2002 dan diidentifikasi di Laboratorium Taksonomi Tumbuhan, Jurusan Biologi, Fakultas MIPA Universitas Padjadjaran, Indonesia. Contoh herbarium dari tanaman tersebut tersimpan di Herbarium Jurusan Biologi FMIPA, Unpad.

\section{Bahan Kimia}

Kolom kromatografi dilakukan pada Silika gel G60 Merck (70-230 Mesh) dan Inertsil ODS (Fuji silysia), analisis kromatografi lapis tipis pada plat Silika gel Merck $\mathrm{GF}_{254} 0,2 \mathrm{~mm}$, noda pada kromatografi lapis tipis divisualisasi di bawah sinar ultra violet pada 254 dan 367 $\mathrm{nm}$ atau dengan penampak noda $10 \%$ asam sulfat dalam etanol yang diikuti dengan pemanasan.

\section{Peralatan}

Titik leleh tidak terkoreksi; rotasi optik diukur dengan menggunakan Horiba model SEPA-300 polarimeter; Spektra UV dicatat pada Hitachi model U-3210 spectrophotometer; IR spectra pada Perkin-Elmer 1760X dengan KBr; Spektra massa dicatat pada JEOL JMS-DX300; Spektra; ${ }^{1} \mathrm{H}$ dan ${ }^{13} \mathrm{C}-\mathrm{NMR}$ diperoleh dengan menggunakan JEOL JNM A-500 
spectrophotometer dengan TMS sebagai standard dalam.

\section{Uji Hayati terhadap ulat sutera ${ }^{13)}$}

Larva ulat sutera yang akan digunakan untuk uji hayati diletakkan pada makanan buatan yang dibeli dari Nippon Nosan Kogyo Co., Ltd. Terhadap 1 gram makanan buatan, $100 \quad 1$ ektrak metanol atau jumlah tertentu dari sampel yang akan diuji di tambahkan pada cawan petri. Setelah pelarutnya diuapkan lima ekor larva ulat sutera instar ke tiga diletakkan pada cawan petri tersebut, dan laju mortalita diamati setelah 24 jam pada suhu $25^{\circ} \mathrm{C}$ setelah perlakuan awal.

\section{Ekstraksi dan isolasi}

Daun segar K. daigremontiana diekstraksi secara tuntas dengan metanol pada suhu kamar. Ekstrak metanol yang diperoleh selanjutnya dipekatkan dan dipartisi antara diklorometan dan air sehingga dihasilkan ekstrak diklorometan aktif insektisida. Ekstrak diklorometan aktif selanjutnya dipartisi antara etil asetat dan air dihasilkan ektrak aktif etil asetat. Ekstrak etil asetat yang diperoleh dikeringkan dengan natrium sulfat anhidrat, dan dipekatkan pada tekanan rendah sehingga dihasilkan residu berwarna coklat. Residu $(12,8$ g) dikromatografi pada Silika gel 60 (70-230 mesh) dengan eluen $n$-heksan dan peningkatan rasio etil asetat, dan etil asetat dengan peningkatan rasio metanol menghasilkan dua fraksi aktif, eluat $100 \%$ etil asetat dan $10 \%$ metanol dalam etil asetat.

Fraksi yang terelusi dengan $100 \%$ etil asetat selanjutnya dipisahkan berturut-turut dengan kolom kromatografi pada Silika gel 60 dengan sistem pelarut kloroform:metanol (49:1) dan $n$-heksan:aseton (7:3) serta pada ODS dengan sisitem pelarut metanol:air (2:3) diikuti dengan kristalisasi dalam metanol sehingga dihasilkan suatu senyawa aktif insektisida $(14,6$ $\mathrm{mg})$.

\section{Senyawa aktif (Daigremontianin)}

Daigremontianin, kristal prisma tak berwarna; titik leleh $269-271{ }^{\circ} \mathrm{C}$; [ ] ${ }_{\mathrm{D}}^{20}+12,6^{\circ}$ (c 0,095 , $\mathrm{MeOH}) ; \quad \mathrm{UV}$ maks (MeOH) nm ( ): 300 (6.100); IR $\mathrm{v}_{\text {maks }}(\mathrm{KBr})$ : 3445, 2882, 1709, dan $1122 \mathrm{~cm}^{-1}$; MALDI TOF-MS m/z $487[\mathrm{M}+\mathrm{H}]^{+}$; NMR ${ }^{1} \mathrm{H}$ - dan ${ }^{13} \mathrm{C}$-NMR (Tabel 1).

\section{HASIL DAN PEMBAHASAN}

Ekstrak metanol dari daun segar cocor bebek (Kalanchoe daigremontaiana) dipekatkan dan dipartisi antara diklorometan dan air. Ekstrak diklorometan menunjukkan aktivitas insektisida terhadap ulat sutera. Ekstrak diklorometan selanjutnya dipartisi antara $n$ heksan dan metanol yang mengandung 10\% air. Lapisan bawah yang aktif selanjutnya diekstraksi dengan etil asetat. Dengan menggunakan aktivitas insektisida untuk mengikuti pemisahan, ekstrak etil asetat dipisahkan dengan kombinasi kromatografi kolom pada Silika gel 60 dan ODS dihasilkan suatu senyawa aktif insektisidal.

Senyawa aktif memberikan rumus formula $\mathrm{C}_{26} \mathrm{H}_{30} \mathrm{O}_{9}$ berdasarkan data MALDI TOF-MS bersama dengan data spektra NMR ${ }^{1} \mathrm{H}$ dan ${ }^{13} \mathrm{C}$ (Tabel 1).

Tabel 1. Data NMR Daigremontianin ${ }^{\mathrm{a}}$

\begin{tabular}{|c|c|c|}
\hline $\begin{array}{c}\text { Posisi } \\
\text { karbon }\end{array}$ & $\begin{array}{l}{ }^{13} \mathrm{C}-\mathrm{NMR} \\
\delta_{\mathrm{C}} \text { (mult.) }\end{array}$ & $\begin{array}{c}{ }^{1} \mathrm{H}-\mathrm{NMR} \\
\delta_{\mathrm{H}}(\text { Integral, mult., } J \text { Hz) }\end{array}$ \\
\hline 1 & $73,2(d)$ & $5,10(1 \mathrm{H}, \mathrm{d}, 4,3$ \\
\hline 2 & $27,6(t)$ & $\begin{array}{l}1,92(1 \mathrm{H}, \mathrm{dt}, 1,5,14,0) \\
2,31(1 \mathrm{H}, \mathrm{ddd}, 4,3,6,1,14,0)\end{array}$ \\
\hline 3 & $67,2(d)$ & $4,36(1 \mathrm{H}, \mathrm{d}, 1,5)$ \\
\hline 4 & $33,3(\mathrm{t})$ & $\begin{array}{l}2,04(1 \mathrm{H}, \mathrm{m}) \\
2,14(1 \mathrm{H}, \mathrm{m})\end{array}$ \\
\hline 5 & $74,6(\mathrm{~s})$ & \\
\hline 6 & $33,2(t)$ & $\begin{array}{l}1,74(1 \mathrm{H}, \mathrm{m}) \\
2,02(1 \mathrm{H}, \mathrm{m})\end{array}$ \\
\hline 7 & $22,1(\mathrm{t})$ & $\begin{array}{l}1,42(1 \mathrm{H}, \mathrm{m}) \\
2,17(1 \mathrm{H}, \mathrm{m})\end{array}$ \\
\hline 8 & 39,8 (d) & $2,22(1 \mathrm{H}, \mathrm{m})$ \\
\hline 9 & $45,1(\mathrm{~d})$ & $1,58(1 \mathrm{H}, \mathrm{dd}, 1,5,12,5)$ \\
\hline 10 & $52,4(\mathrm{~s})$ & \\
\hline 11 & 72,0 (d) & $4,98(1 \mathrm{H}, \mathrm{dd}, 3,0,12,5)$ \\
\hline 12 & 211,7 (s) & \\
\hline 13 & $61,9(\mathrm{~s})$ & \\
\hline 14 & $85,0(\mathrm{~s})$ & \\
\hline 15 & $32,0(t)$ & $\begin{array}{l}1,42(1 \mathrm{H}, \mathrm{m}) \\
1,73(1 \mathrm{H}, \mathrm{m})\end{array}$ \\
\hline 16 & $27,7(\mathrm{t})$ & $\begin{array}{l}2,09(1 \mathrm{H}, \mathrm{m}) \\
2,45(1 \mathrm{H}, \mathrm{m})\end{array}$ \\
\hline 17 & $40,4(d)$ & $4,07(1 \mathrm{H}, \mathrm{dd}, 6,7,9,8)$ \\
\hline 18 & $16,9(q)$ & $0,92(3 \mathrm{H}, \mathrm{s})$ \\
\hline 19 & 208,7 (d) & $10,41(1 \mathrm{H}, \mathrm{d}, 2,1)$ \\
\hline 20 & $120,1(\mathrm{~s})$ & \\
\hline 21 & $150,2(d)$ & $7,38(1 \mathrm{H}, \mathrm{dd}, 0,9,2,4)$ \\
\hline 22 & $146,2(d)$ & $7,65(1 \mathrm{H}, \mathrm{dd}, 2,4,9,8)$ \\
\hline 23 & $115,9(d)$ & $6,29(1 \mathrm{H}, \mathrm{dd}, 0,9,9,8)$ \\
\hline 24 & $161,9(\mathrm{~s})$ & \\
\hline 25 & $110,6(\mathrm{~s})$ & \\
\hline 26 & $25,6(q)$ & $1,46(3 \mathrm{H}, \mathrm{s})$ \\
\hline
\end{tabular}

adiukur dalam $\mathrm{CDCl}_{3}$ pada $500 \mathrm{MHz}$ untuk ${ }^{1} \mathrm{H}$ dan 125 $\mathrm{MHz}$ untuk ${ }^{13} \mathrm{C}$ 
Tabel 1 menunjukkan bahwa senyawa aktif mempunyai dua belas ekuivalensi ikatan rangkap. Spektra NMR ${ }^{1} \mathrm{H}-$ dan ${ }^{13} \mathrm{C}$ senyawa aktif sangat mirip dengan senyawa bryophyllin, ${ }^{8,9)}$ kecuali hilangnya sinyal dari metilena pada $\delta_{\mathrm{H}} 1,41(1 \mathrm{H}, \mathrm{t}, J=12,5 \mathrm{~Hz})$, dan $1,67(1 \mathrm{H}, \mathrm{m})\left(\delta_{\mathrm{C}} 51,1\right)$ seperti yang diamati untuk senyawa aktif, dan munculnya sinyal untuk gugus keton pada $\delta_{\mathrm{C}} 211,7$, diduga bahwa senyawa aktif adalah analog keto dari bryophyllin A.

Untuk menentukan posisi dari gugus keto pada senyawa aktif tersebut, percobaan HMBC (Heteronuclear multiple bond connectivity) dilakukan (Gambar 2). Signal dari Me-18 $\left(\delta_{\mathrm{H}} 0,92\right)$ dan $\mathrm{H}-11\left(\delta_{\mathrm{H}} 4,98\right)$ berkorelasi dengan $\mathrm{C}-12\left(\delta_{\mathrm{C}} 211,7\right)$, menunjukkan bahwa senyawa aktif adalah 12-keto dari bryophyllin A. Hasil pengamatan ini bersama dengan kemiripan data spectra dan sifat-sifat fisikokimia yang diperoleh sebelumnya, ${ }^{12)}$ senyawa aktif diidentifikasikan sebagai daigremontianin.

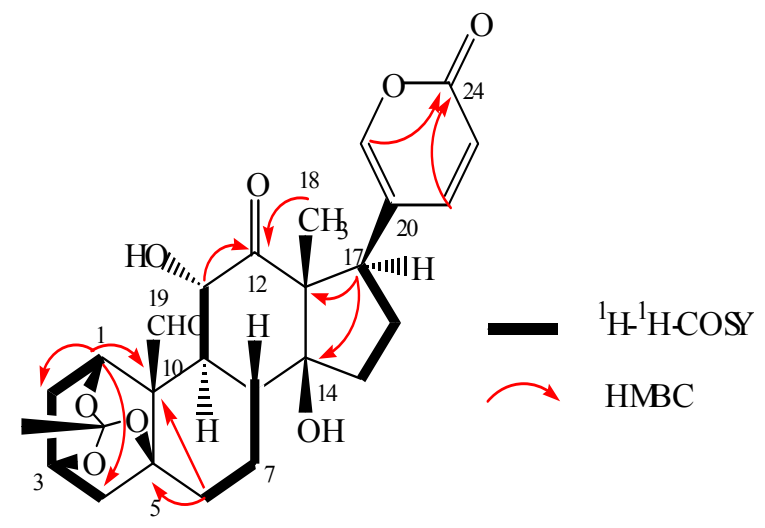

Gambar 2. Spektra ${ }^{1} \mathrm{H}-{ }^{1} \mathrm{H}-\mathrm{COSY}$, dan HMBC terpilih dari daigremontianin

Aktivitas insektisida senyawa daigremontianin diuji terhadap instar ke tiga ulat sutera (Bombyx mori). Pada uji oral, senyawa daigremontianin menunjukkan aktivitas insektisida yang sangat kuat dengan $\mathrm{LD}_{50} 0,9 \mu \mathrm{g} / \mathrm{g}$ diet.

\section{KESIMPULAN}

Senyawa daegremontianin menunjukkan aktivitas insektisidal yang kuat terhadap instar ke tiga ulat sutera (Bombyx mori) dengan $\mathrm{LD}_{50} 0,9 \mu \mathrm{g} / \mathrm{g}$ diet.

\section{UCAPAN TERIMA KASIH}

Penulis mengucapkan terima kasih kepada Dr. Tomoyuki Fujita dan Dr. Kohki Akiyama, Laboratory of Natural Products Chemistry, Division of Applied Biological Chemistry, Graduate School of Agriculture and Life Sciences, Osaka Prefecture University, Osaka, Japan, atas bantuan pengukuran spektra NMR dan MS. Terima kasih juga tertuju pada Drs Joko Kusmoro, Laboratorium Taksonomi Tumbuhan, Jurusan Biologi, Fakultas MIPA, Universitas Padjadjaran, untuk pengumpulan dan identifikasi bahan tumbuhan.

\section{DAFTAR PUSTAKA}

1. Balandrin, M.F., Klocke, J.A., Wurtele, E.S., and Bollinger, Wm. H., Natural plant chemicals: source of industrial and medicinal materials. Science, 228, 1154-1160 (1985).

2. Fukami, H., and Nakajima, M., Rotenone and the rotenoids. In "Naturally Occurring Insecticides", eds. Jacobson, M., and Crosby, D.G., Dekker, New York, pp. $71-79$ (1971).

3. Ishaaya, I., and Horowitz. A. R, Insecticides with novel modes of action, an overview. In "Insecticides with Novel Mode of Action, Mechanism and Application", eds. Ishaaya, 1., and Degheele, D., Springer-Verlag, Berlin, pp. 1-25 (1998).

4. Matsui, M., and "Yamamoto, I., pyrethroids. In "Naturally Occurring Insecticides", eds. Jacobson, M., and Crosby, D. G., Dekker, New York, pp. 3-70 (1971).

5. Schmeltz, I, Nicotine and other tobacco alkaloids. In "Naturally Occurring Insecticides", eds. Ja.cobson, M., and Crosby, D. G., Dekker, New York, pp. 99-136 (1971). 
6. Secoy, D. M., and Smith, A. E., Use of plants in control ofagricultural and domestic pests. Econ. Bot, .37,28-57 (1983).

7. Supratman, U., Fujita, T., Akiyama, K., and Hayashi, H., 2000. New insecticidal bufadienolide, bryophyllin $\mathrm{C}$, from Kalanchoe pinnata. Biosci. Biotechnol. Biochem. 64, 13091311.

8. Supratman, U., Fujita, T., Akiyama, K., and Hayashi, H., 2001. Insecticidal compounds from Kalanchoe daigremontiana. Phytochemistry, $\mathbf{5 8}$, 311-314.

9. Heyne, K., "Tumbuhan Berguna Indonesia" 1987, Badan Penelitian dan Pengembangan, Depatemen Kehutunan, Indonesia, Jakarta, halaman, 845-846.
10. Sjamsu Hidayat, S. S dan Hutapea, J. R., 1991, "Tanaman Obat Indonesia" Badan Penelitian dan Pengembangan, Departemen Kesehatan, Indonesia, Jakarta, halaman. 220-221.

11. Wagner, H., Fischer, M., and Lotter, H., 1985, Isolation and structure determination of daigremontianin, a novel bufadienolida dari Kalanchoe daigremontiana, Planta Med., 169170.

12. Hayashi, H., Takiuchi, K., Murao, S., Arai, M., 1989. Structure and insecticidal activity of new indole alkaloids, okaramines $\mathrm{A}$ and $\mathrm{B}$, from Penicillium simplicissimum AK-40. Agri. Biol. Chem, 53, 461-469. 